\title{
Simulation of the Kinetics of the Autoclave Dissolution of Copper and Nickel Sulfides in the Presence of Oxygen
}

\author{
S. V. Kniss*, S. S. Naboichenko**, and V. P. Zhukov*** \\ Ural Federal University, ul. Mira 19, Yekaterinburg, 620002 Russia \\ *e-mail: bt_work@mail.ru \\ **e-mail:mhnfm@mail.ustu.ru,s.a.petrova@ustu.ru \\ ***e-mail: zhukovv.p@mail.ru
}

\begin{abstract}
Kinetic regularities of the oxidative autoclave dissolution of iron, copper, and nickel sulfides when leaching the ore of the Shanuch deposit are investigated in controllable experimental conditions. It is shown that the dissolution rate of sulfides is limited by the oxygen absorption.
\end{abstract}

Keywords: copper and nickel sulfides, oxygen absorption, leaching

DOI: $10.3103 / \mathrm{S} 1067821213060102$

The kinetics of the oxidative autoclave dissolution of iron sulfides when leaching the ore of the Shanuch deposit was previously described mathematically based on the data on the average process rate [1], and the assumption was formulated that the total process rate is limited by the oxygen absorption.
This study is aimed at verifying this assumption for nickel and copper sulfides with the evaluation of the process rate every $10 \mathrm{~min}(\Delta \tau)$ of the experiment.

We preliminarily calculated the current absorption rate of oxygen during the dissolution of iron sulfides according to the equation

$$
V_{\mathrm{Fe}}=\frac{(\text { Solid:Liquid }) V_{\mathrm{pulp}} C_{\mathrm{Me}}-1.13 \times 0.635 \times 9\left(D_{\mathrm{O}_{2}} \tau_{\mathrm{c}}\right)^{0.5} F_{\mathrm{p}} C_{\mathrm{aq}} / 23}{\Delta \tau},
$$

where $v_{\mathrm{Fe}}$ is the absorption rate, $\mathrm{mol}_{\mathrm{Fe}} / \mathrm{min} ; 0.635$ is the stoichiometric coefficient, which takes into account the consumption of $\mathrm{O}_{2}$ by the corresponding reactions; 23 and 9 are the total number of moles of oxygen and sulfide iron according to the reaction stoichiometry; $C_{\mathrm{Me}}$ is the metal concentration in the solution, $\mathrm{g} / \mathrm{dm}^{3}$; $D_{\mathrm{O}_{2}}$ is the diffusivity of oxygen in the pulp; $\tau_{\mathrm{c}}$ is the contact time, $\mathrm{s} ; F_{\mathrm{p}}$ is the parabola area, $\mathrm{m}^{2}$; and $C_{\mathrm{aq}}$ is the amount of oxygen dissolved in water, $\mathrm{g} / \mathrm{dm}^{3}$.

The experimental and calculated rates of autoclave leaching of iron sulfides found under these conditions are presented in the table. It follows from the tabulated data that the difference between the calculated and experimental data varies from 3.8 to $20.6 \%$ for $70 \mathrm{~min}$ of leaching, when the highest process rate is observed.

We accept that the limiting stage of oxygen absorption is valid in the course of the experiment. To evalu- ate the absorption obstacles during the dissolution of sulfides of copper (chalcopyrite) and nickel (pentlandite), we processed the kinetic data by the method of current rates with $\Delta T=10 \mathrm{~min}$.

We start from the fact that sulfides are dissolved according to the stoichiometry of the following reactions:

$$
\begin{aligned}
& \mathrm{CuFeS}_{2}+4 \mathrm{O}_{2}=\mathrm{CuSO}_{4}+\mathrm{FeSO}_{4} \\
& 4 \mathrm{Fe}_{4.5} \mathrm{Ni}_{4.5} \mathrm{~S}_{8}+70.5 \mathrm{O}_{2}+14 \mathrm{H}_{2} \mathrm{O} \\
&= 18 \mathrm{NiSO}_{4}+9 \mathrm{Fe}_{2} \mathrm{O}_{3}+14 \mathrm{H}_{2} \mathrm{SO}_{4} .
\end{aligned}
$$

The experimental conditions are as follows: the temperature is $413-453 \mathrm{~K}$, the oxygen pressure is $0.4 \mathrm{MPa}, \mathrm{pH}$ of the solution is 1 , and the process duration is $2 \mathrm{~h}$. Absorption equations for nickel and copper sulfides, similarly to (1), have the form

$$
\begin{gathered}
V_{\mathrm{Ni}}=\frac{(\text { Solid:Liquid }) V_{\mathrm{pulp}} C_{\mathrm{Me}}-1.13 \times 0.329 \times 9\left(D_{\mathrm{O}_{2}} \tau_{\mathrm{c}}\right)^{0.5} F_{\mathrm{p}} C_{\mathrm{aq}} / 31.75}{\Delta \tau}, \\
V_{\mathrm{Cu}}=\frac{(\text { Solid:Liquid }) V_{\mathrm{pulp}} C_{\mathrm{Me}}-1.13 \times 0.037 \times 1\left(D_{\mathrm{O}_{2}} \tau_{\mathrm{c}}\right)^{0.5} F_{\mathrm{p}} C_{\mathrm{aq}} / 4}{\Delta \tau},
\end{gathered}
$$


Experimental and calculated dissolution rates of iron sulfides, $\mathrm{mol}_{\mathrm{Fe}} / \mathrm{min}$

\begin{tabular}{|c|c|c|c|c|c|c|c|c|c|c|c|c|}
\hline \multirow{2}{*}{$t,{ }^{\circ} \mathrm{C}$} & \multicolumn{12}{|c|}{ Time, min } \\
\hline & 10 & 20 & 30 & 40 & 50 & 60 & 70 & 80 & 90 & 100 & 110 & 120 \\
\hline \multicolumn{13}{|c|}{ Experimental data } \\
\hline 140 & 2.31 & 1.16 & 0.77 & 0.58 & 0.46 & 0.39 & 0.33 & 0.29 & 0.26 & 0.23 & 0.21 & 0.19 \\
\hline 150 & 3.26 & 1.63 & 1.09 & 0.82 & 0.65 & 0.54 & 0.47 & 0.41 & 0.36 & 0.33 & 0.30 & 0.27 \\
\hline 160 & 2.37 & 1.19 & 0.79 & 0.59 & 0.47 & 0.40 & 0.34 & 0.30 & 0.26 & 0.24 & 0.22 & 0.20 \\
\hline 170 & 3.32 & 1.66 & 1.11 & 0.83 & 0.66 & 0.55 & 0.47 & 0.42 & 0.37 & 0.33 & 0.30 & 0.28 \\
\hline 180 & 2.79 & 1.39 & 0.93 & 0.70 & 0.56 & 0.46 & 0.40 & 0.35 & 0.31 & 0.28 & 0.25 & 0.23 \\
\hline \multicolumn{13}{|c|}{ Calculated data } \\
\hline 140 & 1.84 & 1.43 & 1.09 & 0.80 & 0.58 & 0.41 & 0.30 & 0.26 & 0.27 & 0.35 & 0.48 & 0.67 \\
\hline 150 & 2.59 & 2.01 & 1.52 & 1.10 & 0.76 & 0.50 & 0.32 & 0.22 & 0.20 & 0.26 & 0.40 & 0.62 \\
\hline 160 & 1.89 & 1.47 & 1.11 & 0.81 & 0.57 & 0.39 & 0.27 & 0.21 & 0.21 & 0.28 & 0.40 & 0.58 \\
\hline 170 & 2.64 & 2.05 & 1.54 & 1.10 & 0.75 & 0.48 & 0.29 & 0.18 & 0.14 & 0.19 & 0.32 & 0.53 \\
\hline 180 & 2.21 & 1.71 & 1.26 & 0.87 & 0.54 & 0.28 & 0.07 & 0.08 & 0.16 & 0.19 & 0.16 & 0.06 \\
\hline
\end{tabular}

where 0.329 and 0.037 are the stoichiometric coefficients, which take into account the $\mathrm{O}_{2}$ consumption by the corresponding reactions; 31.75 and 9 is the total number of the moles of oxygen and sulfide nickel; and 4 and 1 is the total number of the moles of oxygen and

$\boldsymbol{V}$, mole $_{\mathrm{Cu}} / \mathrm{min}$

(a)

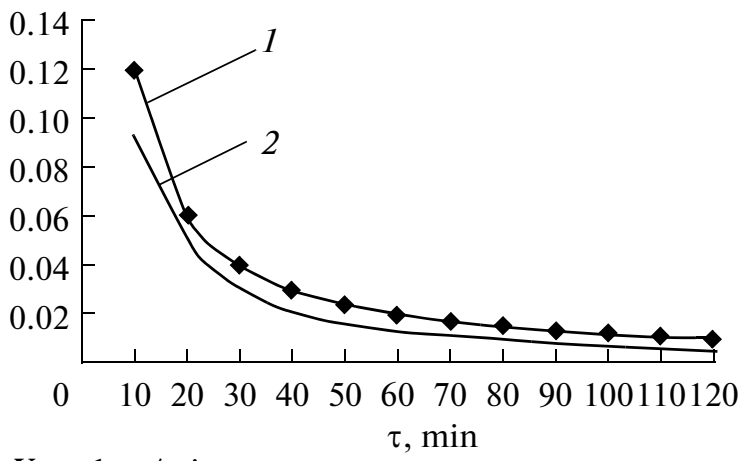

$\boldsymbol{V}$, mole $_{\mathrm{Ni}} / \mathrm{min}$

(b)

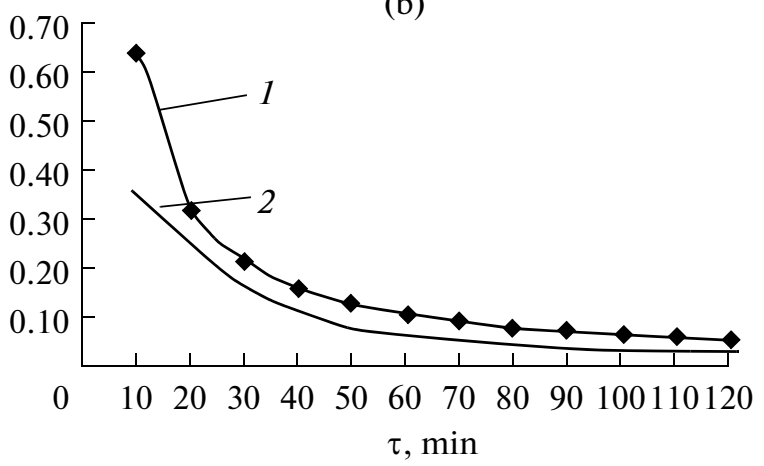

(1) Experimental and (2) calculated dissolution rates of sulfides of (a) copper and (b) nickel depending on the experiment duration. sulfide copper according to the stoichiometry of reactions.

The adequacy of models (1), (4), and (5) to the experimental data is confirmed with the help of $F$ statistics with a confidence probability of $95 \%$.

The experimental and calculated temporal dependences of the dissolution rate of nickel and copper sulfides are shown in the figure. Our data indicate that satisfactory coincidence occurs by the order of magnitudes of $v$. The difference between the calculated and experimental data was $4.5-42.2 \%$ for the dissolution of nickel sulfide and $3.5-21.0 \%$ for copper sulfide at leaching time of $70 \mathrm{~min}$. The largest divergence in the initial instant of the process is apparently explained by the noticeable occurrence of reactions at $\Delta \tau<10 \mathrm{~min}$.

Additionally, using methodology [1], we analyzed the possible limiting phases of the following process stages:

(i) the oxygen absorption with the pulp;

(ii) the mass transfer of the dissolved gas to the surface of solid particles (external diffusion) along with the solvent into the zone of the chemical reaction;

(iii) the chemical interaction on the surface of solid particles;

(iv) the removal of the reaction products into the solution bulk.

We found the following calculated rates for iron, nickel, and copper sulfides, $\mathrm{mol} / \mathrm{min}:(1.2-1.4) \times 10^{-7}$ for the second stage, $(1.1-1.7) \times 10^{-3}$ for the third stage, and approximately $10^{-6}$ for the fourth stage.

Thus, the calculated rates of stages 2-4 strongly differ from the experimental data of the table and the figure, which is additional confirmation of the possible dissolution of iron, nickel, and copper sulfides in the oxygen absorption mode. 


\section{CONCLUSIONS}

The kinetics of the autoclave oxidative dissolution of iron, nickel, and copper sulfides is analyzed in controllable experimental conditions every $10 \mathrm{~min}$ in the experiment. The assumption is formulated that the dissolution rate of metal sulfides is governed by the stage of oxygen absorption. In order to intensify leaching, it is reasonable to increase the oxygen pres- sure and the intensity of pulp stirring, which determine the efficiency of the mass-exchange processes.

\section{REFERENCES}

1. Kniss, S.V., Naboichenko, S.S., and Zhukov, V.P., Russ. J. Non-Fer. Met., 2012, no. 3, p. 218.

Translated by N. Korovin 